\title{
Generalized Simpson-Newton's Method for Solving Nonlinear Equations with Cubic Convergence
}

\author{
J. Jayakumar \\ Department of Mathematics, Pondicherry Engineering College, Pondicherry-605014, India
}

\begin{abstract}
In the recent past, different variants of Newton's method with cubic convergence have become popular iterative methods to find the roots of non-linear equations. In this paper, a new class of Newton's method for solving a single nonlinear equation is proposed. This method is the generalization of Simpson's integration rule applied on the Newton' theorem. Some of the existing methods become special cases of this method. Third order convergence of the proposed methods is established. Numerical examples are provided. A comparison study is done to show the efficiency of this method for different parameters in the method.
\end{abstract}

Keywords: Iterative Method, Newton's Method, Non-linear equation, Third order convergence, Simpson integration method.

\section{Introduction}

A frequently occurring and most important problem of applied mathematics and engineering is to find a root of the equation

$$
f(x)=0
$$

where $\mathrm{f}: \mathrm{D} \subseteq \mathrm{R} \rightarrow \mathrm{R}$ for an open interval $\mathrm{D}$ is a scalar function. Newton's method is one of the famous iterative methods to solve equation (1). It is well known that it has quadratic convergence. The iterative formula of Newton's method is given by

$$
x_{n+1}=x_{n}-\frac{f\left(x_{n}\right)}{f^{\prime}\left(x_{n}\right)}, n=0,1,2 \ldots
$$

By improving Newton's method, Chebyshev [1] derived a cubic convergent iterative method which requires computing of second derivative of the function (1). Weerakoon et al [2] improved the order of convergence to three via trapezoid rule on Newton's theorem and obtained Arithmetic Newton's method. Hasanov et al [3] modified Newton's method with a third order convergent method by using Simpson's rule. Nedzhibov [4] gave many classes of iterative methods using different quadrature rules. Later many authors [5, $6,7,9]$ proposed different variants of Newton's method of order three. Babajee et al [8] took eight different variants of Newton's method and analyzed the relationship between them. They explored the properties of arithmetic mean Newton's method and explained third order accuracy via the Tailor's series expansion. Tibor et al [10] suggested geometric mean Newton's method for simple and multiple roots and showed this method is of order three for simple roots and order one for multiple roots. Ababneh [11] modified Newton's method using contra-harmonic mean instead of Arithmetic mean. The advantage of all the above methods is that they require only the first derivative of the function and has cubic convergence.

In this paper, we propose a generalization of the Simpson-Newton's method $[3,12]$ where Simpson's integration rule is applied for approximating the integral in the Newton's theorem. We find that some of the existing methods are special cases of the proposed method. Third order convergence of the proposed method is established. In Section II, we present some definitions related to our study. Some known variants of Newton's method are discussed in Section III. Section IV presents the new method and its analysis of convergence and Section V gives numerical results. Finally, a discussion is carried out on the merits and demerits of the proposed method in Section VI.

\section{Preliminaries}

Definition 2.1 [2]: Let $\alpha \in R, x_{n} \in R, \mathrm{n}=0,1,2, \ldots$. Then the sequence $\left\{x_{n}\right\}$ is said to converge to $\alpha$ if $\lim _{n \rightarrow \infty}\left|x_{n}-\alpha\right|=0$. If, in addition, there exist a constant $c \geq 0$, an integer $n_{0} \geq 0$ and $\mathrm{p} \geq 0$ such that for all $\stackrel{n \rightarrow \infty}{n>0},\left|x_{n+1}-\alpha\right| \leq c\left|x_{n}-\alpha\right|^{\mathrm{P}}$, then $\left\{x_{n}\right\}$ is said to converge to $\alpha$ with order $\mathrm{p}$. If $\mathrm{p}=2$ or 3 , the convergence is said to be quadratic or cubic respectively.

Definition 2.2[2]: Let $\alpha$ be a root of the function (1)and suppose that $x_{n-1}, x_{n}$ and $x_{n+1}$ are three successive iterations closer to the root $\alpha$. Then, the computational order of convergence (COC) denoted by $\rho$ can be approximated using the formula $\approx \frac{\ln \left|\left(x_{n}+1-\alpha\right) /\left(x_{n}-\alpha\right)\right|}{\ln \left|\left(x_{n}-\alpha\right) /\left(x_{n}-1-\alpha\right)\right|}$. 


\section{Some Known Variants of Newton's Method}

Let $\alpha$ be a simple root of a sufficiently differentiable function $f(x)$. Consider the numerical solution of the function $f(x)=0$. From Newton's theorem, we have

$f(x)=f\left(x_{n}\right)+\int_{x_{n}}^{x} f^{\prime}(t) d t$.

Arithmetic Mean Newton's method (AN): By using the trapezoidal rule in (3), we obtain

$\int_{x_{n}}^{x} f^{\prime}(t) d t \approx \frac{\left(x-x_{n}\right)}{2 k}\left[f^{\prime}\left(x_{n}\right)+2 \sum_{i=1}^{k-1} f^{\prime}\left(x_{n}-\frac{i f\left(x_{n}\right)}{k f^{\prime}\left(x_{n}\right)}\right)+f^{\prime}(x)\right]$.

From equations (3) and (4), a new approximation $x_{\mathrm{n}+1}$ for $x$ when $\mathrm{k}=1$, we get arithmetic mean Newton's method [2]

$x_{n+1}=x_{n}-\frac{2 f\left(x_{n}\right)}{f^{\prime}\left(x_{n}\right)+f^{\prime}\left(x_{n+1}\right)}$.

Since equation (5) is implicit, we can overcome this implicit nature by the use of Newton's iterative step (2). However, we denote $x_{\mathrm{n}+1}$ as $\mathrm{y}_{\mathrm{n}}$ here-in-afterwards, where

$y_{n}=x_{n}-\frac{f\left(x_{n}\right)}{f^{\prime}\left(x_{n}\right)}, n=0,1,2, \ldots$.

Midpoint Newton's method (MN): If the integral in (3) is approximated using the midpoint integration rule instead of trapezoidal rule, we get the midpoint Newton's method [6]

$x_{n+1}=x_{n}-\frac{f\left(x_{n}\right)}{f^{\prime}\left(\frac{x_{n}+y_{n}}{2}\right)}, n=0,1,2, \ldots$, where $y_{n}$ is calculated from $(6)$.

Trapezoidal-Newton's method (TN): From equations (3) and (4), one obtains a new approximation for $\mathrm{k}=2$ $x_{n+1}=x_{n}-\frac{4 f\left(x_{n}\right)}{f^{\prime}\left(x_{n}\right)+2 f^{\prime}\left(\frac{x_{n}+y_{n}}{2}\right)+f^{\prime}\left(y_{n}\right)}$,

where $y_{n}$ is calculated from (6). The above method is called as Trapezoidal-Newton's method [4].

Simpson-Newton's method (SN): Simpson's $\frac{1}{3}$ integration rule is used to find the value of the integral in (3) to obtain the Simpson-Newton's method [3] as follows:

$\int_{x_{n}}^{x} f^{\prime}(t) d t \approx \frac{\left(x-x_{n}\right)}{6}\left[f^{\prime}\left(x_{n}\right)+4 f^{\prime}\left(\frac{x+x_{n}}{2}\right)+f^{\prime}(x)\right]$.

Simplifying and computing for $x_{\mathrm{n}+1}$ from equation (7), one obtains a new approximation

$x_{n+1}=x_{n}-\frac{6 f\left(x_{n}\right)}{f^{\prime}\left(x_{n}\right)+4 f^{\prime}\left(\frac{x_{n}+x_{n}+1}{2}\right)+f^{\prime}\left(x_{n+1}\right)}$.

Since equation (8) is implicit, replacing $\mathrm{x}_{\mathrm{n}+1}$ with $y_{n}$ (calculated from (6)) on the right hand side, we get

$x_{n+1}=x_{n}-\left(\frac{6 f\left(x_{n}\right)}{f^{\prime}\left(x_{n}\right)+4 f^{\prime}\left(\frac{x_{n}+y_{n}}{2}\right)+f^{\prime}\left(y_{n}\right)}\right), n=0,1,2, \ldots$.

Harmonic-Simpson-Newton's method (HSN): After dividing numerator and denominator in equation (9) by 2 and using harmonic mean instead of arithmetic mean, we obtain Harmonic-Simpson-Newton's method [12]

$x_{n+1}=x_{n}-\left(\frac{3 f\left(x_{n}\right)}{\frac{2 f^{\prime}\left(x_{n}\right) f^{\prime}\left(y_{n}\right)}{f^{\prime}\left(x_{n}\right)+f^{\prime}\left(y_{n}\right)}+2 f^{\prime}\left(\frac{x_{n}+y_{n}}{2}\right)}\right), n=0,1,2, \ldots$.

\section{Generalized Simpson-Newton's Method}

Introducing arbitrary parameters $\mathrm{m}, \mathrm{m}_{1}, \mathrm{~m}_{2}$ and $\mathrm{m}_{3}$ in the second term of equation (9), we obtain $x_{n+1}=x_{n}-\left(\frac{m f\left(x_{n}\right)}{m_{1} f^{\prime}\left(x_{n}\right)+m_{2} f^{\prime}\left(\frac{x_{n}+y_{n}}{2}\right)+m_{3} f^{\prime}\left(y_{n}\right)}\right), n=0,1,2, \ldots$,

where $\mathrm{m}_{1}+\mathrm{m}_{2}+\mathrm{m}_{3}=\mathrm{m}$ and $y_{n}$ is calculated from (6).

Remark 1. (a) If $\mathrm{m}=\mathrm{m}_{1}=1$ and $\mathrm{m}_{2}=\mathrm{m}_{3}=0$, we get Newton's method. (b) If $\mathrm{m}=2, \mathrm{~m}_{1}=\mathrm{m}_{3}=1$ and $\mathrm{m}_{2}=0$, we get Arithmetic Newton's method. (c) If $\mathrm{m}=\mathrm{m}_{2}=1$ and $\mathrm{m}_{1}=\mathrm{m}_{3}=0$, we get Midpoint Newton's method. (d) If $\mathrm{m}=4, \mathrm{~m}_{1}=\mathrm{m}_{3}=1$ and $\mathrm{m}_{2}=2$, we get Trapezoidal Newton's method. (e) If $\mathrm{m}=6, \mathrm{~m}_{1}=\mathrm{m}_{3}=1$, and $\mathrm{m}_{2}=4$, we get Simpson-Newton's method. Hence, we call this method (10) Generalized Simpson-Newton's method (GSN).

\section{Analysis of Convergence}

In the following theorem, we establish the cubic convergence of the present method (GSN).

Theorem 4.1: Let $\alpha \in D$, be a simple zero of a sufficiently differentiable function $f: D \subseteq R \rightarrow R$ for an open interval D. If $x_{0}$ is sufficiently closer to $\alpha$, then the method (10) has third order convergence.

Proof. Let $\alpha$ be a simple zero of function $f(x)=0$. (That is, $f(\alpha)=0$ and $f^{\prime}(\alpha) \neq 0$ ). 
By expanding $f\left(x_{n}\right)$ and $f^{\prime}\left(x_{n}\right)$ by Taylor series about $\alpha$, we obtain

$f\left(x_{n}\right)=f^{\prime}(\alpha)\left[e_{n}+c_{2} e_{n}^{2}+c_{3} e_{3}^{3}+O\left(e_{n}^{4}\right) \ldots\right]$,

$f^{\prime}\left(x_{n}\right)=f^{\prime}(\alpha)\left[1+2 c_{2} e_{n}+3 c_{3} e_{n}^{2}+4 c_{4} e_{n}^{3}+O\left(e_{n}^{4}\right) \ldots\right]$,

where $c_{k}=\frac{f^{(k)}(\alpha)}{k ! f^{\prime}(\alpha)}, k=2,3, \ldots$ and $e_{n}=x_{n}-\alpha$. Dividing equation (11) by (12), we get

$\frac{f\left(x_{n}\right)}{f^{\prime}\left(x_{n}\right)}=e_{n}-c_{2} e_{n}^{2}+2\left(c_{2}^{2}-c_{3}\right) e_{n}^{3}+O\left(e_{n}^{4}\right)$. Hence, we get from (6)

$y_{n}=\alpha+c_{2} e_{n}^{2}+2\left(c_{3}-c_{2}^{2}\right) e_{n}^{3}+O\left(e_{n}^{4}\right)$

Also, we have

$\frac{y_{n}+x_{n}}{2}=\alpha+\frac{1}{2} e_{n}+\frac{1}{2} c_{2} e_{n}^{2}+\left(c_{3}-c_{2}^{2}\right) e_{n}^{3}+O\left(e_{n}^{4}\right)$.

Expanding $f^{\prime}\left(y_{n}\right)$ by Tailor's series about $\alpha$ and using (13), we get

$f^{\prime}\left(y_{n}\right)=f^{\prime}(\alpha)\left[1+2 \mathrm{c}_{2}^{2} \mathrm{e}_{\mathrm{n}}^{2}+\mathrm{O}\left(\mathrm{e}_{\mathrm{n}}^{3}\right)\right]$.

Again expanding $f^{\prime}\left(\frac{\mathrm{x}_{\mathrm{n}}+y_{n}}{2}\right)$ by Tailor's series about $\alpha$ and using (14), we get

$f^{\prime}\left(\frac{x_{n}+y_{n}}{2}\right)=f^{\prime}(\alpha)\left[1+c_{2} e_{n}+\left(c_{2}^{2}+\frac{3}{4} c_{3}\right) e_{n}^{2}+O\left(e_{n}^{3}\right)\right]$.

From (12), (15), (16) and taking $\mathrm{m}_{1}+\mathrm{m}_{2}+\mathrm{m}_{3}=\mathrm{m}$, we have

$\mathrm{m}_{1} f^{\prime}\left(\mathrm{x}_{\mathrm{n}}\right)+\mathrm{m}_{2} f^{\prime}\left(\frac{\mathrm{x}_{\mathrm{n}}+y_{n}}{2}\right)+\mathrm{m}_{3} f^{\prime}\left(\mathrm{y}_{\mathrm{n}}\right)=\mathrm{m} f^{\prime}(\alpha)\left[1+\mathrm{c}_{2}\left(\frac{2 \mathrm{~m}_{1}+\mathrm{m}_{2}}{\mathrm{~m}}\right) \mathrm{e}_{\mathrm{n}}+\left(\mathrm{c}_{2}^{2}\left(\frac{2 \mathrm{~m}_{1}+\mathrm{m}_{2}}{\mathrm{~m}}\right)+3 \mathrm{c}_{3}\left(\frac{\mathrm{m}_{1}+\frac{\mathrm{m}_{2}}{4}}{\mathrm{~m}}\right)\right) \mathrm{e}_{\mathrm{n}}^{2}+\mathrm{O}\left(\mathrm{e}_{\mathrm{n}}^{3}\right)\right]$.

Then from equation (11) and (17), we get

$\frac{m f\left(x_{n}\right)}{\mathrm{m}_{1} \mathrm{f}^{\prime}\left(\mathrm{x}_{\mathrm{n}}\right)+\mathrm{m}_{2} \mathrm{f}^{\prime}\left(\frac{\mathrm{x}_{\mathrm{n}}+y_{n}}{2}\right)+\mathrm{m}_{3} \mathrm{f}^{\prime}\left(\mathrm{y}_{\mathrm{n}}\right)}=e_{n}+e_{n}^{2}\left[c_{2}-\frac{c_{2}}{m}\left(2 m_{1}+m_{2}\right)\right]+e_{n}^{3}\left[c_{3}\left(1-3\left(\frac{\mathrm{m}_{1}+\frac{\mathrm{m}_{2}}{4}}{\mathrm{~m}}\right)\right)+\mathrm{c}_{2}^{2}(-2+\right.$

$2 \mathrm{~m} 1+\mathrm{m} 2 \mathrm{~m} 2+$ Oen 4 .

The above equation (18) is substituted in (10) to get

$x_{n+1}=x_{n}-\left[e_{n}+e_{n}^{2}\left[c_{2}-\frac{c_{2}}{m}\left(2 m_{1}+m_{2}\right)\right]+e_{n}^{3}\left[c_{3}\left(1-3\left(\frac{\mathrm{m}_{1}+\frac{\mathrm{m}_{2}}{4}}{\mathrm{~m}}\right)\right)+\mathrm{c}_{2}^{2}\left(-2+\left(\frac{2 \mathrm{~m}_{1}+\mathrm{m}_{2}}{\mathrm{~m}}\right)^{2}\right)\right]+O\left(e_{n}^{4}\right)\right]$.

Since $x_{n}=e_{n}+\alpha$, we finally obtain from (19)

$\left.e_{n+1}=e_{n}^{2}\left[-c_{2}+\frac{c_{2}}{m}\left(2 m_{1}+m_{2}\right)\right]+e_{n}^{3}\left[c_{3}\left(-1+3\left(\frac{\mathrm{m}_{1}+\frac{\mathrm{m}_{2}}{4}}{\mathrm{~m}}\right)\right)+\mathrm{c}_{2}^{2}\left(2-\left(\frac{2 \mathrm{~m}_{1}+\mathrm{m}_{2}}{\mathrm{~m}}\right)^{2}\right)\right]+O\left(e_{n}^{4}\right)\right]$.

Remark 2. It can be easily verified that the coefficient of $e_{n}^{2}$ will be zero in the above equation for all the variants of Newton's method given in Section III. Hence, cubic convergence is established for GSN for all those parameters $\left(\mathrm{m}_{1}, \mathrm{~m}_{2}\right.$ and $\left.\mathrm{m}\right)$ satisfying the condition $2 m_{1}+m_{2}=m$.

\section{Numerical Examples}

Table 1

\begin{tabular}{|c|c|c|c|c|c|c|c|c|}
\hline \multirow[b]{2}{*}{$f(x)$} & \multirow[b]{2}{*}{$\mathrm{X}_{0}$} & \multicolumn{6}{|c|}{ Number of iterations } & \multirow[t]{2}{*}{ Root } \\
\hline & & NM & $\mathrm{AN}$ & $\mathrm{MN}$ & TN & SN & HSN & \\
\hline \multirow{2}{*}{$f_{1}(x)=x^{3}+x^{2}-2$} & 1.5 & 6 & 5 & 4 & 5 & 5 & 4 & \multirow[t]{2}{*}{$\alpha=1$} \\
\hline & 3 & 8 & 6 & 6 & 6 & 6 & 5 & \\
\hline \multirow[t]{2}{*}{$f_{2}(x)=\operatorname{Sin} x+x \operatorname{Cos} x$} & 1.3 & 6 & 5 & 5 & 5 & 5 & 5 & \multirow[t]{2}{*}{$\alpha=2.028757838110434$} \\
\hline & 3 & 6 & 5 & 4 & 4 & 4 & 4 & \\
\hline \multirow[t]{2}{*}{$f_{3}(x)=\mathrm{x}^{2}-\mathrm{e}^{\mathrm{x}}-3 \mathrm{x}+2$} & 3 & 7 & 5 & 5 & 5 & 5 & 5 & \multirow{2}{*}{$\alpha=0.257530285439861$} \\
\hline & 5 & 9 & 7 & 6 & 6 & 6 & 6 & \\
\hline \multirow[t]{2}{*}{$f_{4}(x)=\mathrm{x} \mathrm{e}^{\mathrm{x}}-1$} & 3 & 9 & 7 & 6 & 7 & 6 & 6 & \multirow[t]{2}{*}{$\alpha=0.567143290409784$} \\
\hline & 4.5 & 11 & 8 & 8 & 8 & 8 & 7 & \\
\hline \multirow[t]{2}{*}{$f_{5}(x)=x^{3}-10$} & 3 & 6 & 5 & 5 & 5 & 5 & 4 & \multirow[t]{2}{*}{$\alpha=2.154434690031884$} \\
\hline & -1 & 7 & $\mathrm{NC}$ & 6 & 11 & 7 & 5 & \\
\hline \multirow{2}{*}{$f_{6}(x)=\mathrm{e}^{\mathrm{x}}+\mathrm{x}-20$} & 10 & 13 & 9 & 9 & 9 & 9 & 8 & \multirow[t]{2}{*}{$\alpha=2.842438953784447$} \\
\hline & 5 & 8 & 6 & 4 & 6 & 6 & 5 & \\
\hline
\end{tabular}

In this section, we present the numerical results of the proposed method (GSN). Also, we examine GSN for different values of $\mathrm{m}, \mathrm{m}_{1}, \mathrm{~m}_{2}$ and $\mathrm{m}_{3}$. Different functions and number of iterations to find their roots are given in Table 1. Computational Order of Convergence (COC) and the Number of Function Evaluation (NOFE) are given in Table 2. We note that the function $f_{5}(x)$ is not convergent for $\mathrm{x}_{0}=-1$, by AN even with 100 iterations but convergent for all other cases. Numerical computations are done in the Matlab software with 
double precision accuracy and the results are presented.

We have used the following stopping criteria for the iterative process:

$$
\left|x_{n+1}-x_{n}\right|+\left|f\left(x_{n+1}\right)\right|<\varepsilon, \text { where } \varepsilon=10^{-14} .
$$

Table 2

\begin{tabular}{|c|c|c|c|c|c|c|c|c|c|c|c|c|c|}
\hline \multirow[t]{2}{*}{$f(x)$} & \multirow{2}{*}{$\mathrm{X}_{0}$} & \multicolumn{6}{|c|}{$\mathrm{COC}$} & \multicolumn{6}{|c|}{ NOFE } \\
\hline & & NM & AN & $\mathrm{MN}$ & $\mathrm{TN}$ & SN & HSN & NM & AN & $\mathrm{MN}$ & $\mathrm{TN}$ & SN & HSN \\
\hline \multirow[t]{2}{*}{$f_{1}(x)$} & 1.5 & 2.00 & 2.99 & 2.75 & 2.99 & 2.99 & 2.80 & 12 & 15 & 12 & 20 & 20 & 16 \\
\hline & 3 & 2.00 & 2.98 & 2.99 & 2.99 & 2.99 & 2.80 & 16 & 18 & 18 & 24 & 24 & 20 \\
\hline \multirow[t]{2}{*}{$f_{2}(x)$} & 1.3 & 1.99 & 3.82 & 3.17 & 3.07 & 3.12 & 3.08 & 12 & 15 & 15 & 20 & 20 & 20 \\
\hline & 3 & 1.99 & 4.10 & 2.71 & 2.88 & 2.60 & 2.70 & 12 & 15 & 12 & 16 & 16 & 16 \\
\hline \multirow[t]{2}{*}{$f_{3}(x)$} & 3 & 2.00 & 3.04 & 3.39 & 2.91 & 2.66 & 2.78 & 14 & 15 & 15 & 20 & 20 & 20 \\
\hline & 5 & 2.00 & 3.01 & 3.29 & 3.20 & 3.16 & 2.69 & 18 & 21 & 18 & 24 & 24 & 24 \\
\hline \multirow[t]{2}{*}{$f_{4}(x)$} & 3 & 2.00 & 2.99 & 2.88 & 2.99 & 2.84 & 2.93 & 18 & 21 & 18 & 28 & 24 & 24 \\
\hline & 4.5 & 2.00 & 2.96 & 2.99 & 2.98 & 2.99 & 2.91 & 22 & 24 & 24 & 32 & 32 & 28 \\
\hline \multirow[t]{2}{*}{$f_{5}(x)$} & 3 & 2.00 & 2.99 & 2.99 & 2.99 & 2.99 & 2.81 & 12 & 15 & 15 & 20 & 20 & 16 \\
\hline & -1 & 2.00 & $\mathrm{NC}$ & 2.91 & 3.01 & 3.02 & 2.95 & 14 & $\mathrm{NC}$ & 18 & 44 & 36 & 20 \\
\hline \multirow[t]{2}{*}{$f_{6}(x)$} & 10 & 2.00 & 2.93 & 3.00 & 2.98 & 2.99 & 2.94 & 26 & 27 & 27 & 36 & 28 & 32 \\
\hline & 5 & 2.00 & 2.99 & 3.00 & 2.99 & 2.99 & 2.94 & 16 & 18 & 12 & 24 & 24 & 20 \\
\hline
\end{tabular}

$\mathrm{NC}$ - Not Convergent

\section{Discussion}

The basic advantage of the present method is that it is a generalized class of Newton's method using the Simpson's formula applied on the Newton's theorem. The proposed new class of methods has the advantage of evaluating only the first derivative of $\mathrm{f}(\mathrm{x})$, third order convergence and requires less number of iterations to achieve the desired accuracy. Also, we find that (see Remark 1) some of the existing methods given in Section III are special cases of the proposed GSN. Few methods like Trapezoidal and Simpson Newton's methods require four function evaluation which is one extra compared to other third-order convergent Newton methods. However, this drawback in efficiency is compensated by the decrease in the number of iterations. The motivation behind this contribution is to bring in certain existing methods under one class of method, the Generalized Simpson Newton's method.

\section{References}

[1] M.K.Jain, S.R.K. Iyengar, R.K.Jain, Numerical Methods for Scientific and Engineering Computation, New Age International, $6^{\text {th }}$ edition, 2012.

[2] S. Weerakoon. T.G.I. Fernando, A Variant of Newton's method with accelerated third-order convergence, Applied Mathematics Letters 13 (8) (2000) 87-93.

[3] V. I. Hasanov, I. G. Ivanov, G. Nedjibov, A new modification of Newton's method, Applied Mathematics andEngineering 27 (2002) $278-286$

[4] G. Nedzhibov, On a few iterative methods for solving nonlinear equations. Application of Mathematics in Engineering and Economics'28, in: Proceeding of the XXVIII Summer school Sozopol' 02, pp.1-8, Heron press, Sofia, 2002.

[5] M. Frontini, E. Sormoni, Some variants of Newton's method with third order convergence, Applied Mathematics and Computation 140 (2003) 419-426.

[6] A.Y. Ozban, Some new variants of Newton's method, Applied Mathematics Letters 17 (2004) 677-682.

[7] H.H.H. Homeier, On Newton-type methods with cubic convergence, Journal of Computational and AppliedMathematics 176 (2005) 425-432.

[8] D.K.R. Babajee, M.Z. Dauhoo, An analysis of the properties of the variants of Newton's method with third order convergence, Applied Mathematics and Computation 183 (2006) 659-684.

[9] K. Jisheng, L.Yitian, W. Xiuhua, Third-order modification of Newton's method, Journal of Computational and Applied Mathematics 205 (2007) $1-5$.

[10] T. Lukic, N. M. Ralevic, Geometric mean Newton's method for simple and multiple roots, Applied Mathematics Letters 21 (2008) $30-36$

[11] O.Y. Ababneh, New Newton's method with third-order Convergence for solving nonlinear equations, World Academy of Science, Engineering and Technology 61 (2012) 1071-1073.

[12] J. Jayakumar and M. Kalyanasundaram, Modified Newton's method using harmonic mean for solving nonlinear equations, IOSR Journal of Mathematics 7(4) (2013) 93-97. 